\title{
Neural bases underlying Native or Foreign word production, and Language switching
}

\author{
Choong-Myung Kim ${ }^{1 *}$ \\ ${ }^{1}$ Division of Language, Speech and Psychological Therapy, Gwangju University \\ 모국어와 외국어의 단어산출 및 언어 간 전환에 따른 뇌 활성화 \\ 과정 \\ 김충명** \\ '광주대학교 언어·심리치료학부
}

\begin{abstract}
The neural bases underlying within or between-language picture naming was investigated by using event-related fMRI. The present suudy explorered the following two goals: The first is to compare cortical activation areas relevant to naming process in native and foreign language, and to decide whether the activation pattern of the foreign word will be the same as native words or not. The next is to find the cerebral areas involved only in alternating language switching between native and foreign language condition. Differential activation patterns were observed for language switching against one-language. Both naming tasks all activated the left inferior frontal gyrus (LIFG) as expected. However the differences in naming between languages were reflected in the activation amount of the LIFG, namely more activation in naming the native language than the foreign language. Especially, naming of the foreign word from English showed the similar area and size in activation with native language suggesting that the process of borrowed noun resembles that of native common noun. And the language switching between languages newly activated the right middle frontal gyrus as well as the left inferior frontal areas. The right middle frontal gyrus engagement in switching conditions obviously identified that right hemisphere is recruited in code switching possibly with respect to meta-cognition controlling language index at a subconscious level.
\end{abstract}

요 약 본 연구는 사건관련 fMRI를 이용하여 언어 내 및 언어 간 그림명명 과제를 수행하는 동안 모국어와 외래어 명사관련 피질 활성화 영역을 비교해 보고, 특히 외래어의 활성화 패턴이 모국어에 동조되는지를 알아보았다. 아울러 과제수행 언어가 정해지지 않은 임의적 언어전환 조건에 관여하는 활성화 영역도 연구대상이었다. 실험결과, 한 가지 수행언어만으로 제한되 는 과제에서는 모국어 및 외래어 모두 좌측 하전두회(LIFG) 활성화가 일어났으나 모국어의 활성화 정도가 더 컸으며, 특히 외래어 명명 시 모국어와의 활성화 강도는 약화된 반면 영역분포는 유사한 결과를 얻었다. 이는 외래어가, 외국어가 아닌 모국어에 동조되었음을 시사한다 하겠다. 마지막으로 언어전환 조건에서의 실험에서는 좌측 하전두피질 외에 우측 중전두피 질이 관여함을 발견함으로써 실험수준이 아닌 일상수준의 다언어 사용에 있어, 의식이전의 언어 간 부호전환에 관여하는 우반구의 상대적인 기여와 역할을 시사하는 결과를 얻었다.

Key Words : language switching; foreign word, right hemisphere engagement, event-realted fMRI

\footnotetext{
This study was conducted by research funds from Gwangju University in 2014.

"Corresponding Author : Choong-Myung Kim (Gwangju Univ.)

Tel: +82-62-670-549 email: cmkim@gwangju.ac.kr 


\section{Introduction}

Bilingual aphasic syndrome occurring after the damage to brain has taken our attention because of the $\mathrm{CO}^{-}$occurrence with language switching, mixing, and pathological mixing as well as diverse patterns of recoveries[1-3]. The bilingual aphasics often switch from one language to other languages, alternating their language type involuntarily or unconsciously. Language switching or mixing is also present in normal bilinguals, but such an apparent phenomena in the brain-damaged differ in that the pattern of language performance is uncontrollable irrespective of their specific foreign language use. Even when only one language is needed to depict a picture or event in a stationary scene, or within a sentence, the patients tend to repeat the same behavioral pattern described above. So the patterns is not hard to differentiate each other, language switching syndrome can be classified as pragmatic disorder and its lesion is mainly over bilateral prefrontal lobes. On the other hand language mixing as one of aphasic disorder similar to Wernicke's aphasia has its lesion in ambient of posterior rolandic fissure[4-5].

Main focus of the current paper we are paying attention to is how bilingual language will be represented in the brain. More recent researches related with bilingual language switching were concentrated on using neuroimaging technique such as PET(positron emission tomography), fMRI(functional magnetic resonance imaging), etc[6]. There is a study showing overlapping of activation in Broca's and Wernicke's area for each language by early bilingual $\llcorner$ whereas an activation in only Broca's area by late bilinguals suggesting that late second language is represented differently from early one[7]. Also there are reports that investigated switching within-language lexical switches in English-Spain bilinguals using ERP[8-9]. Their results show lexical switches enhanced N400 component across centro-parietal region whereas code switches elicited an increased N400 mainly over fronto-central area, and large posterior positivity (LPC) peak around at $600 \mathrm{~ms}$ suggesting that switching cost may vary depending on whether the lexical item comes from within the native language or from another language. There were many studies reported the cognitive processes underlying language switching. The first model to account for the switching mechanism is a neurocognitive model recruiting 5 briain regions associated with cognitive control: attention related area(dorsolateral prefrontal cortex, bilateral supramarginal gyrus), error detection related area(anterior cingulate cortex), and cortical activation mediating area(caudate)[10-11]. The second is what is called Luk model including left IFG(inferiror frontal gyrus), left middle temporal gyrus(MTG), left middle frontal gyrus (MFG), right precentral gyrus, right STG(superior temporal gyrus), midline supplementary motor area, and bilateral caudate nuclei. These areas related to cognitive control are involved according to the levels of the baseline task(i,e. low-level baseline: fixation alone, high-level baseline: L1 or L2 language production)[12].

The present study adopting L1 or L2 language production load as a baseline task has two goals here. The first is to examine the brain cortical areas related with picture naming in the different kinds of languages: Korean, English, and the borrowed words from English. Specifically our main focus in this respect is how naming noun of the foreign word from English will be represented in the brain. The second aim is to investigate the neural bases of language switching from one language to the other and explore the cognitive model adapted in the present study. The ultimate question we addressed here is to search what kind of neural structure join together in switching languages.

\section{Methods}

\subsection{Participants}


13 healthy right-handed volunteers with a mean age of 25.8 (range 21 to 28 ) participated in this study. They were all proven to be right-handed throuth the right-handness assessment (Edinburgh Handedness Inventory) test[13]. In the current experiment the participants were all native Korean speakers (L1) learned English (L2) as a foreign language in classroom instruction after the age of 12 . The parameters of general characteristics related with the participants are described in Table 1 . In addition, all had normal or corrected to normal vision and no subject had a known history of neurological or psychiatric disorders. The written informed consent was obtained from all participants according to protocols approved by the Ethical Commitee of Gwangju University of Korea before starting off all experimental procedures.

[Table 1] Specification of general characteristics for the participants

\begin{tabular}{|l|l|l|}
\hline \multicolumn{1}{|c|}{ parameter } & \multicolumn{1}{|c|}{ sub-parameter } & \multicolumn{1}{c|}{$\mathrm{N}(\%)$} \\
\hline age & $21-25$ & $9(69.2)$ \\
\hline & $26-28$ & $4(30.8)$ \\
\hline sex & male & $8(61.5)$ \\
\hline & female & $5(38.5)$ \\
\hline education & undergraduate & $10(76.9)$ \\
\hline & graduate & $3(23.1)$ \\
\hline residence & capital region & $12(92.3)$ \\
\hline & district & $1(7.7)$ \\
\hline
\end{tabular}

\subsection{Materials and Procedures}

The materials of the experiment consisted of the object pictures. The stimuli were the line drawing objects. Subjects were asked to name the stimuli in the native or foreign language. And the conditions were counter-balanced according to the order of participation.

[Table 2] Specification of procedure in the two experiment conditions

\begin{tabular}{|c|c|c|}
\hline & Common Noun & Borrowed noun \\
\hline $\begin{array}{c}\text { One-language } \\
\text { condition }\end{array}$ & Korean/English & Korean/English \\
\hline $\begin{array}{c}\text { Switching } \\
\text { condition }\end{array}$ & Korean or English & - \\
\hline
\end{tabular}

Subjects performed three sets of picture naming tasks, and the design was run in an event -related fMRI experiments. The experiments were largely composed of 2 sessions. The first is one-language condition including picture naming tasks using either of already fixed two languages and the second consisted of language switching conditions containing two kinds of dot in which what type of language subjects do not know to respond with as shown in Table 2. In the session, participants were required to generate Korean or English covert naming of visually presented pictures according to the number of points dotted on upper left [Fig. 1]. And the point was shown at random to prevent subjects from guessing language type with which to comply. Subjects were asked to respond in Korean as seen one dot presented together with a picture, or respond in English as seen two dot. All experimental tasks were conducted to keep utterance covert so as to minimize the movement acquiring the image.

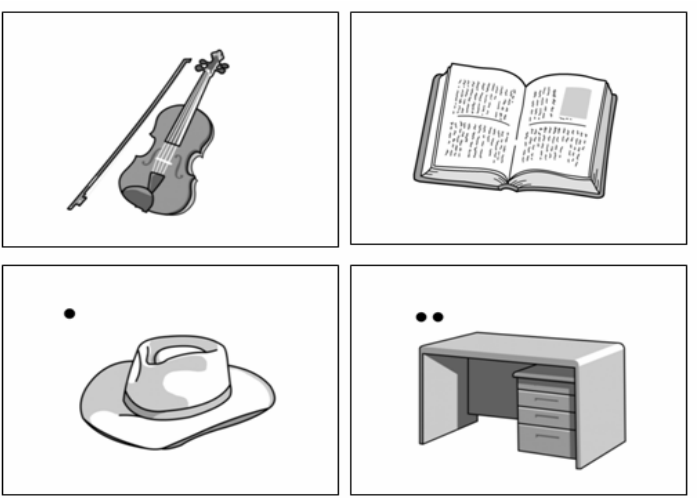

[Fig. 1] An example of picture naming set. Violin (Korean noun borrowed from English) sounds /vaiolin / in Korean, book (normal noun) sounds /tsek/ in Korean; The picture of 1 dot should be read in Korean, 2 dot in English.

\subsection{Image Data Acquisition and Analysis}

Subjects lay supine in a ISOL 3.0T forte MRI scanner equipped with EPI, their heads being secured to minimize movement artifacts. During fMRI scanning stimuli were presented visually on a computer screen. 
Prior to data acquisition a conventional sagittal scout scan was first obtained from which the functional images were overlaid for each subject. Across the complete brain volume by means of a EPI-BOLD (Echo Planner Imaging- Blood Oxygen Level Dependent) sequence $(\mathrm{TR} / \mathrm{TE}=3000 / 35 \mathrm{msec}, 64$ x64 Matrix, FOV $22 \mathrm{~cm}$, flip angle $80^{\circ}$ ) Total volume image in each session comprising 204 phases for 612 seconds were collected for each subject over 20 slices $(5 \mathrm{~mm}$ thickness/no gap). Activation was detected by the BOLD contrast mechanism.

Image processing and statistical analysis were performed offline on a PC using SPM(statistical parametric mapping) software, which allows for realignment of functional images, corregistration with structural images, spatial normalization, smoothing, and statistical inference ( $\mathrm{z}$-value cut-off, uncorrected $\mathrm{p}<$ 0.001). Spatial normalization with $\mathrm{T} 1$ template and smoothing with FWHM(full-width at half-maximum) $7.5 \mathrm{~mm}$ Gaussian filter were conducted. The brain region in this paper were transformed by the Talairach Deamon Client from the MNI(Montreal Neurological Institute) coordinates to the Talairach-Tournoux coordinates[14]. Because of the motion artifact, one of all participants was not included on the statistical analysis.

Statistical inferences were drawn from general linear model as it is implemented in SPM. Linear contrasts were calculated for the comparisons between conditions and then its images were extracted to extend statistical inference about the level of activity differences to the population images. Activation are shown for clusters of 15 neighboring voxels surpassed an initial uncorrected threshold of $\mathrm{p}<.001$ and had a corrected $\mathrm{p}^{-}$-value of $\mathrm{p}$ $<.05$ on cluster level.

\section{Results}

\subsection{One-language Condition}

Statistical comparison between conditions revealed the activation mainly in frontal regions like this. First of all, noun naming in L1 induced increased activation mainly in a network including the left inferior/middle frontal (IFG/MFG; BA 45/11), left precentral gyrus (PCG; BA 6), each related with involving word production and with activation for the preparation of articulation respectively. There were additional activation in bilateral occipital area (BA 17, 18, 19) showing visual effect due to picture stimuli as well.

The following noun naming in L2 revealed the activation in the similar cerebral areas (IFG,MFG, PCG) having less activation with the native language as illustrated in 2 blue circles within Fig. 2 . and the right homologue of left IFG in addition. In the view of magnitude of activation areas picture naming related to common noun in L2 produced the decreased activation in frontal regions compared to the areas in L1.
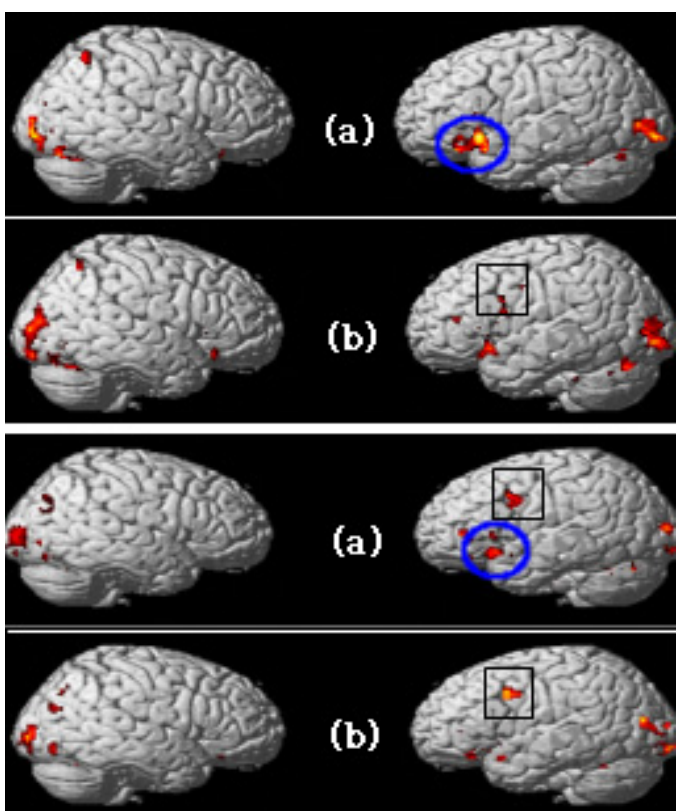

[Fig. 2] Activation map (threshold at uncorrected p < .001 , corrected on cluster level at 0.05 ) of the one-language condition only in Korean (2 pictures in upper panel), only in English (2 pictures lower). native common noun (a), noun of the foreign word from English (b). 
Lastly in L1 and L2 session for the noun borrowed from English, there are some difference 2 and similarities between the foreign language related responses(noun in L2, borrowed noun in L1 and L2). Different activation was found in PCG(BA 6) among noun in L2, borrowed noun in L1, and L2 in the viewpoint of the magnitude of activation indexed by the number of cluster, namely there were little activation in noun in L2 condition, while the rest condition showed dominant and similar activation in PCG. This area is known for the preparation of articulation for verbal motor planning. On the other hand, similar activations were commonly found in LIFG at three conditions described above with attenuated activation compared to the condition of noun in $\mathrm{L} 1$ as depicted in 3 squares within Fig. 2.

Irrespective of L1 or L2, this similar activation seem to suggest that the noun of foreign word from English was processed like the word production of the native language [Fig. 2]. Specific cerebral regions and activation levels were verified in Table 3.

[Table 3] Brain regions where activation was present during the picture naming only in one language condition

\begin{tabular}{|c|c|c|c|c|c|}
\hline & \multicolumn{5}{|c|}{ One-language condition } \\
\hline & \multicolumn{3}{|c|}{ Native Common Noun } & \multicolumn{2}{|c|}{ Foreign Common Noun } \\
\hline & Korean & English & & Korean & English \\
\hline & $(X, Y, \quad T$-value/duste & & & $\alpha, Z, Z$ T-value/duster & \\
\hline \multirow[t]{2}{*}{$\mathbb{F G}(\mathrm{BA} 47,45)$} & $\mathrm{L}(-32,32,-18) 7,38 / 247$ & $L(-42,20,2)$ & $6.15 / 15$ & $\mathrm{~L}(-32,14,-18) 7.92 / 98$ & $L(-30,18,-16) \quad 5.44 / 4$ \\
\hline & & & & $R(34,28,-16) 6.84 / 28$ & $R(32,32,-18) 4.87 / 3$ \\
\hline $\operatorname{MFG}(B A 11,6)$ & $L(-32,34,-6) \quad 5.61 / 247$ & $\mathrm{~L}(-26,26,-16$ & 16) $5.34 / 45$ & $L(-44,10,30) \quad 5.83 / 35$ & $\mathrm{~L}(-30,34,-14) 10.98 / 54$ \\
\hline PCG (BA6,8) & & $L(-50,2,34)$ & $7.6 / 93$ & $L(-44,-4,40) \quad 5.28 / 5$ & $\lfloor(-52,10,40) 9.59 / 85$ \\
\hline
\end{tabular}

\subsection{Switching Condition}

During object naming in the switching condition for Korean shows more activations than one-language conditions. Specifically the quantity in activation of right hemisphere is increased to a significance level especially in right middle frontal gyrus (BA6) as shown in 2 circles within Fig. 3. In conditions of language switching in English, right middle/inferior frontal gyrus shows more activation than in only one-language
English. To confirm the excluding area for only language switching, operation subtraction was conducted between the activation results corresponding language switching and those of one-language condition (uncorrected $p<.001$ ). As shown in Fig. 3 . both language switching conditions of Korean and English are all shows differential activation in right hemisphere without any of left hemisphere activation as shown in 2 squares within Fig 3. Particularly increased activity in BA47 including right hemisphere indicates that there is a need for more effortful cognitive retrieval processing load in less dominant second language as seen in Table 3.

To summarize the results in switching condition, the main suggestion is like that in case of not setting language mode, switching load recruits another involvement of right hemisphere unlike conditions of language already fixed. Specific cerebral regions and activation levels are the following Table 4 .

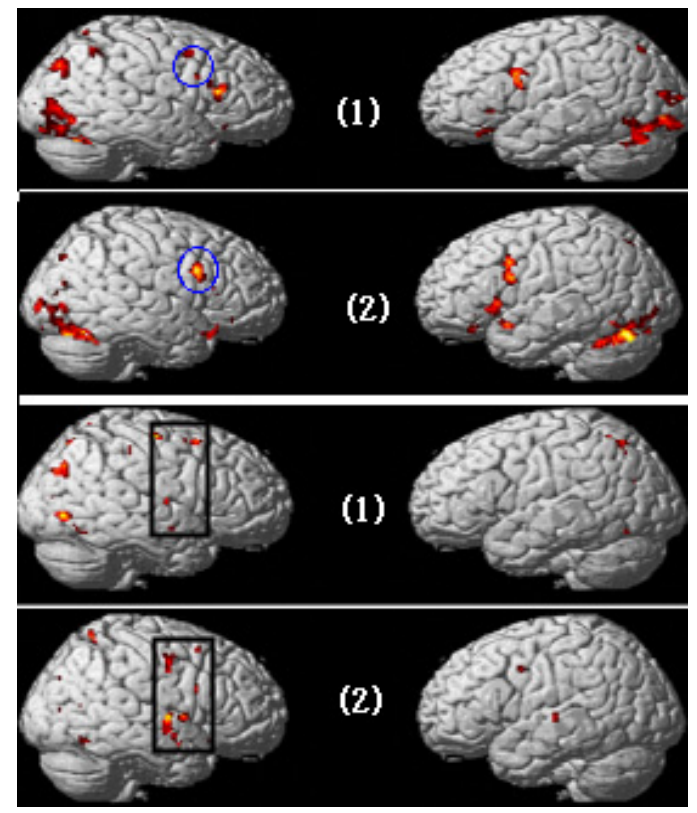

[Fig. 3] Activation map for switching condition in Korean (1), in English (2) in upper 2 panels, and the map of the differential contrast switching minus one-language condition in lower 2 panels (threshold at uncorrected $\mathrm{p}<$ .001 , corrected on cluster level at .05) 
[Table 4] Brain regions where activation was present during the picture naming in switching condition

\begin{tabular}{|c|c|c|}
\hline \multicolumn{3}{|c|}{ switching condition (Common Noun) } \\
\hline & Korean & English \\
\hline & T-value/duster & T-value/cluster \\
\hline \multirow[t]{3}{*}{ IFG (BA 47) } & $\mathrm{L}(-46,8,24) \quad 9.29 / 123$ & $\mathrm{~L}(-46,8,24) \quad 8.42 / 135$ \\
\hline & $\mathrm{L}(-52,10,34) \quad 6.48 / 123$ & $L(-52,8,36) \quad 7.92 / 135$ \\
\hline & $R(50,10,30) \quad 6.07 / 10$ & $\mathrm{R}(46,12,30) 17.77 / 99$ \\
\hline \multirow[t]{2}{*}{ MFG (BA 11, 9) } & $\mathrm{L}(-28,30,-16) 6.87 / 54$ & $\mathrm{~L}(-28,34,-18) 5.61 / 133$ \\
\hline & $R(34,28,-14) \quad 4.9 / 6$ & $R(36,36,-12) \quad 5.21 / 3$ \\
\hline PCG (BA 6) & - & $\mathrm{L}(-4,32,36) \quad 5.92 / 290$ \\
\hline STG & - & $L-42,10,-16) \quad 8.13 / 44$ \\
\hline SPL (BA 7) & $\mathrm{R}(34,-54,48) 6.77 / 337$ & $R(22,-66,38) \quad 5.63 / 52$ \\
\hline
\end{tabular}

\section{Discussion}

The current study was performed to investigate the neural structure related to producing name of picture of object in native or foreign language on the subjects who learned English before and after the age of 12 and reached a level of fluency of speaking in English. Above all, in this study we examined the effects related with language switching between two languages on the cerebral correlates involved in picture naming with a basis of response to one-language condition.

As is well known in general aphasic syndrome like language switching and mixing after brain damage in bilinguals they have diverse characteristics with respect to language production. Particularly the former in question known to take native and foreign language by turns after brain damage occurs irrespective of whoever is the companion of conversation. To the contrary, mixing is said to be scrambled between native and foreign language in the same sentence. Though these syndromes are common to normal bilinguals, brain-damaged patients shows pathologic switching or mixing pattern stated above in language use. Therefore even in the condition under being asked to be said in only one language, the similar behavioral pattern continued which is defined as a pathologic behavior. Some descriptions of code-switching related with language also imply a certain level of linguistic competence in the languages used because the speakers use two languages or dialects simultaneously or interchangeably[15]. In many bilingual or multilingual communities it's a ordinay occurrence and may be defined as normative linguistic behavior[16]. From their studies, we come to know that language switching is not just a kind of dysfluent speech, rather the switching from one code to another is consistent extra-linguistically. But because the switching in such a meaning need the approach related to sociolinguistic behavior, in this current study, switching is limited in a narrow sense which means exchangeability between two languages available in use.

First of all we had to address whether cerebral activation pattern produced by Korean or English picture naming will be alike or not. Specifically how borrowed noun from English is represented on cerebral activation under the same as one-language condition. The next objective was to confirm the areas elicited by picture naming without fixing a specific language type to respond. This is why brain activation areas related with alternating language in practical use is yet not known and can be affected by the relationship between native and foreign language use. Particularly there is few report to date about the results under the condition with which language type to respond is randomly varying. In this respect the results from this study will inform another role of right hemisphere and serve the key to interpretate the right hemisphere activation in language production tasks.

\section{Conclusion}

The main concern in this study was to confirm the activation areas involved in switching condition as well as within-language condition. In this current experiment, we used Event-related fMRI to find the brain area of the processing engendered when a subject encounters unexpected switch from one language to another. To the end we compared the picture naming 
not fixed code-switching with the results produced by fixed one-language condition. As indicated in other studies we also showed that picture naming resulted in activation in frontal cortex which extends to precentral gyrus basically including left inferior frontal gyrus as well as right homologue with a smaller area[17]. These results are in parallel with the findings indicating more effortful semantic retrieval[18]. Particularly in the case of producing the noun of foreign word from English similar pattern of activation was newly observed in the naming of native noun with one-language condition. Lastly we can elucidate new region of interest in the right middle frontal gyrus related only with unexpected language switching as a novel observation. This finding suggests that right hemisphere activation are more involved when given a condition of language switching than that of one-language and its implication is related with a key mediator in cognitive control between languages. In summary unexpected switching between languages is more difficult to alternate code including access to the meaning than to respond with lexical item as expected.

\section{References}

[1] C. Shyamala, E. D. Krupa, B. Sapna, "Language mixing and switching in Malayalam-English bilingual aphasics", Asia Pacific Disability Rehabilitation Journal 15(2), pp.68-76. 2004

[2] P. Mariën, J. Abutalebi, S. Engelborghs, P. P. De Deyn, " "Pathophysiology of language switching and mixing in an early bilingual child with subcortical aphasia" Neurocase: The Neural Basis of Cognition, 11(6), pp.385-98. 2005.

[3] B. Sapna, C. Shyamala, "Code Switching in Normal and Aphasic Kannada-English Bilinguals", ISB4: Proceedings of the 4th International Symposium on Bilingualism, Somerville, MA: Cascadilla Press. pp.306-316. 2005.

[4] F. Fabbro, The neuro-linguistics of bilingualism. Hove, UK: Psychology Press. 1999.

[5] F. Fabbro, M. Skrap, S.Aglioti, "Pathological switching between languages following frontal lesion in a bilingual patient", Journal of Neurology, Neurosurgery, and
Psychiatry, 68, pp.650-652, 2000.

DOI: http://dx.doi.org/10.1136/jnnp.68.5.650

[6] A. E. Hernandez, A. Martinez, K. Kohnert, "In search of the language switch: An fMRI study of picture naming in Spanish-English bilinguals", Brain and Language, 73, pp.421-431, 2000.

DOI: http://dx.doi.org/10.1006/brln.1999.2278

[7] K. H. S. Kim, N. R. Relkin, K. M. Lee, J. Hirsch, "Distinct cortical areas associated with native and second languages", Nature, 388, pp.171-174. 1997.

DOI: http://dx.doi.org/10.1038/40623

[8] E. Moreno, K.edermeier, M.utas, "Switching languages, switching palabras (words): An electrophysiological study of code switching", Brain and Language, 80, pp.188 - .207. 2002.

[9] V. D. M. Maartje, C. Fernando, C. Manuel, A. B. Horacio, "Electrophysiological correlates of language switching in second language learners", Psychophysiology, 48 pp. 44 -54. 2011.

DOI: http://dx.doi.org/10.1111/j.1469-8986.2010.01039.x

[10] T. Hedden, J.D. Gabrieli, "Shared and selective neural correlates of inhibition, facilitation, and shifting processes during executive control", Neuroimage 51(1), pp.421 - 431. 2010.

DOI: http://dx.doi.org/10.1016/j.neuroimage.2010.01.089

[11] J. Abutalebi, D.W. Green, "Bilingual language production: The neurocognition of language representation and control", Journal of Neurolinguistics 20(3), pp.242 - 275. 2007.

DOI: http://dx.doi.org/10.1016/j.jneuroling.2006.10.003

[12] G. Luk, J.A.E. Anderson, F.I.M. Craik, C. Grady, E. Bialystok, "Cognitive control for language switching in bilinguals: A quantitative meta- analysis of functional neuroimaging studies", Language and Cognitive Processes 27(10), pp.1479 - 1488. 2012.

DOI: http://dx.doi.org/10.1080/01690965.2011.613209

[13] R.C. Oldfield, " The assessment and analysis of handedness: The Edinburgh Inventory",. Neuropsychologia 9, pp.97-113. 1971.

DOI: http://dx.doi.org/10.1016/0028-3932(71)90067-4

[14] J. Talairach, P. Tournoux, Co-planar stereotaxic atlas of the human brain. New York: Georg Thieme Verlag. 1988.

[15] J. Gumperz, "Conversational code-switching", In Gumperz, J. (ed.), Discourse Strategies. New York: Cambridge University Press, 59-99. 1982.

DOI: http://dx.doi.org/10.1017/CBO9780511611834.006

[16] L. Duran, "Towards a better understanding of 
code-switching and interlanguage in bilinguality: Implications for bilingual instruction", Journal of Educational Issues of Language Minority Students 14, pp.69-88. 1994.

[17] M. Heng , H. Jiehui Hu, X. Jie i, S. Wen, G. Jianqiao, G. Feng, W. Yuntao, G. Jinjin, Y. Dezhong, "Bilingual Cognitive Control in Language Switching: An fMRI Study of English-Chinese Late Bilinguals", PLoS One 9(9), pp.1-8. 2014.

DOI: http://dx.doi.org/10.1371/journal.pone.0106468

[18] D. Badre, A. D. Wagner, "Left ventrolateral prefrontal cortex and the cognitive control of memory", Neuropsychologia 45, pp.2883 - 2901. 2007.

DOI: http://dx.doi.org/10.1016/j.neuropsychologia.2007.06.015

\section{Choong-Myung Kim}

[Regular member]

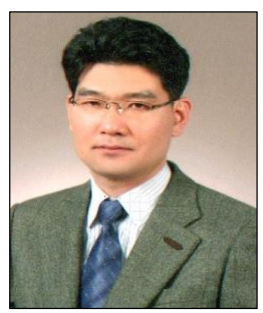

- Feb. 1993 : Seoul Univ., Dept. of Linguistics, MS

- Feb. 2003 : Seoul Univ., Dept. of Cognitive Science, $\mathrm{PhD}$

- May 2004 Feb. 2008 : Korea Univ., Research Prof.

- Mar. 2008 current : Gwangju Univ., Division of Language, speech and Psychology, Prof.

$<$ Research Interests $>$

language acquisition, speech-language pathology, cognitive neuroscience. 